Check for updates

Cite this: RSC Adv., 2019, 9, 40168

Received 21st October 2019

Accepted 25th November 2019

DOI: $10.1039 / c 9 r a 08593 a$

rsc.li/rsc-advances

\section{Catalyst-free visible-light-induced condensation to synthesize bis(indolyl)methanes and biological activity evaluation of them as potent human carboxylesterase 2 inhibitors $\uparrow$}

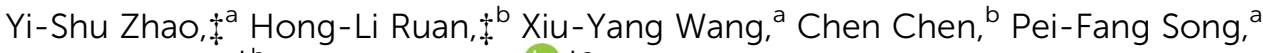 \\ Cheng-Wei Lü*b and Li-Wei Zou (D)*a
}

\begin{abstract}
A mild strategy for visible-light-induced synthesis of bis(indolyl)methanes was developed using aromatic aldehydes and indole as substrates. This reaction could be performed at room temperature under catalyst- and additive-free conditions to synthesize a series of bis(indolyl)methanes in good to excellent yields. In addition, all synthesized bis(indolyl)methanes together with $\beta$-substituted indole derivatives synthesized according to our previous work, were evaluated for their inhibitory effect against human carboxylesterase (CES1 and CES2). Primary structure-activity relationship analysis of all tested compounds showed that the modifications of $\beta$-substituted indole at the $\beta$-site with another indolyl group led to a significant enhancement of the inhibitory effect on CES2, and the bisindolyl structure is essential for CES2 inhibition. These results demonstrated that these bis(indolyl)methanes are potent and selective CES2 inhibitors, which might be helpful for medicinal chemists to design and develop more potent and selective CES2 inhibitors for biomedical applications.
\end{abstract}

\section{Introduction}

Mammalian carboxylesterases (CES, E.C. 3.1.1.1) are key members of the serine hydrolase superfamily, and play important roles in the hydrolytic metabolism of ester-, thioester-, amide-, and carbamate-bond containing endogenous and xenobiotic compounds. ${ }^{1,2}$ In the human body, there are two predominant carboxylesterases, human carboxylesterase 1 (CES1) and human carboxylesterase 2 (CES2). ${ }^{3,4}$ As the major CES distributed in the human intestines and colon, CES2 is mainly known as the enzyme involved in the metabolism of some ester-containing drugs and environmental toxicants. ${ }^{5,6}$ For example, CPT-11, a carbamate prodrug prescribed for the treatment of colorectal cancer, could trigger severe delayed diarrhea due to the overproduction of $\mathrm{SN}-38$ (the hydrolytic product of CPT-11) in the small intestine. ${ }^{7-9}$ Therefore, it is hypothesized that co-administration with potent CES2 inhibitors may ameliorate CPT- 11 caused severe diarrhea in patients and thus improve the therapeutic effect. ${ }^{10,11}$ In addition to the

${ }^{a}$ Institute of Interdisciplinary Integrative Medicine Research, Shanghai University of Traditional Chinese Medicine, Shanghai 201203, People's Republic of China. E-mail: chemzlw@shutcm.edu.cn

${ }^{b}$ School of Chemistry and Chemical Engineering, Liaoning Normal University, Dalian 116029, People's Republic of China. E-mail: chengweilv@126.com

$\dagger$ Electronic supplementary information (ESI) available. See DOI: 10.1039/c9ra08593a

\$ These authors contributed equally to this work. well-known roles of CES2 in xenobiotic metabolism, the enzyme also participates in endogenous metabolism ${ }^{12,13}$ More recently, CES2 has been reported with triacylglycerol and diacylglycerol hydrolase activity, its expression and function in liver are strongly related with several metabolic diseases, such as obesity and non-alcoholic steatohepatitis. ${ }^{13,14}$ Thus, CES2 inhibitors could be used as potential tools for exploring the biological functions of CES2 in complex biological systems.

Indole derivatives are widely distributed in nature and possess beneficial biological activities, including anticancer, ${ }^{15,16}$ antifungal, ${ }^{17}$ anti-inflammatory, ${ }^{18,19}$ and antimicrobial activities. ${ }^{20,21}$ Among them, bis(indolyl)methanes and $\beta$-substituted indole are distinguished skeletons which are important intermediates for chemical synthesis and important pharmacophores. ${ }^{22}$ In view of this, there is already a considerable demand in medicinal and organic chemistry for developing versatile synthetic approaches to these two kinds of compounds and careful study their biological activities. ${ }^{23-28}$ The interest for developing mild and environment-friendly synthetic method of indole derivatives is one thread in our group. ${ }^{29,30}$ Meanwhile, we also focus on the further applications of heterocyclic compounds synthesized in our laboratory.

In recently years, biochemists have made significant breakthrough on the design and development of several highly specific optical substrates for sensing the real activities of CES1 or CES2 in complex biological systems. ${ }^{31-37}$ These newly developed optical substrates have been successfully used for high 
throughput screening of natural or unnatural inhibitors against CES. ${ }^{38-43}$ However, indole and its derivative inhibitors against CES2 with high potency and enhanced selectivity are rarely reported. ${ }^{44,45}$ Based on the wide and beneficial activity of bis(indolyl)methanes and $\beta$-substituted indole derivatives, we were interested in whether these two kinds of compounds have effects against human CES1 and CES2. We have developed some environmentally benign synthetic methodologies for the preparation of $\beta$-substituted indole derivatives. ${ }^{29,30}$ Herein, we provide a relatively simple and environmental friendly reaction condition to synthesized bis(indolyl)methanes. More important, these two types of synthetic compounds have been meticulously screened for inhibitory effects against human CES1 and CES2.

\section{Experiment}

\subsection{Chemicals and reagents}

Fluorescein diacetate (FD), Loperamide (LPA) and bis-p-nitrophenyl phosphate (BNPP) were purchased from TCI (Tokyo, Japan) and their purity was greater than $98 \%$ by HPLC-UV measurement. $\beta$-Substituted indole derivatives $\mathbf{1 a}-\mathbf{p}$ were synthesized according to our previous work. ${ }^{29,30}$ Compounds 1a-p, 4a-p, LPA and BNPP were prepared in DMSO (Tedia, USA) to prepare a stock solution and stored in a refrigerator at $4{ }^{\circ} \mathrm{C}$ until use. The specific fluorescent probes D-luciferin methyl ester (DME) was synthesized in our laboratory. ${ }^{36}$ Ultrapure water (Millipore, Bedford, USA). Human liver microsomes (HLM) purchased from Research Institute for Liver Disease (Shanghai) Co., Ltd. Luciferin detection reagent (LDR) was obtained from Promega Biotech (Madison, USA). Phosphate buffer (PBS) is prepared by ultrapure water and stored in a $4{ }^{\circ} \mathrm{C}$ refrigerator, divided into $\mathrm{pH} 6.5$ and $\mathrm{pH}$ 7.4. All ${ }^{1} \mathrm{H}$ NMR $(500 \mathrm{MHz})$ were recorded on a Bruker Avance spectrometer with chemical shifts reported as ppm (in DMSO- $d_{6}$, TMS as the internal standard).

\subsection{General procedure for the synthesis of indole derivatives} $(\mathbf{4 a - p )}$

A mixture of the appropriate aldehyde $(0.5 \mathrm{mmol}), 2$-methylindole $(1.0 \mathrm{mmol})$ and $1.5 \mathrm{~mL}$ solvent $\left(\mathrm{EtOH}-\mathrm{H}_{2} \mathrm{O} 1: 1, \mathrm{v} / \mathrm{v}\right)$ were added in a $10 \mathrm{~mL}$ Schlenk tube. This solution was stirred under irradiation of blue LEDs (15 W LED light band was used). The reaction was monitored by TLC. After completion, $1 \mathrm{~mL} \mathrm{EtOH}$ was added and vigorously stirred for $10 \mathrm{~min}$ to remove the impurity. Corresponding purified product was obtained after filtered and washed with cold aqueous ethanol. If necessary, product was purified by column chromatography using silica gel (200-300 mesh). (Please note: low power blue LED light band was used in the experiment. Exothermic effect was not obvious.)

The detailed structural characterization of indole derivatives $(\mathbf{4 a}-\mathbf{p})$ are described in the ESI. $\dagger$

\subsection{Florescence-based CES inhibition assays}

2.3.1. Inhibition of indole derivatives on CES1-mediated DME hydrolysis. The inhibitory effects towards CES1 was investigated with DME used as the specific probe substrates for
CES1. ${ }^{36}$ In brief, each compound $(2 \mu \mathrm{L}$, different concentrations according to the initial screening settings) and CES1 enzyme source (HLM, $2 \mu \mathrm{L}, 0.02 \mathrm{mg} \mathrm{mL}^{-1}$, initial concentration) were placed in phosphate buffer ( $94 \mu \mathrm{L}, \mathrm{pH} 6.5)$, add the positive inhibitor BNPP in parallel and incubate for $5 \mathrm{~min}$ in a $37^{\circ} \mathrm{C}$ incubator. The reaction was then initiated by the addition of probe DME ( $2 \mu \mathrm{L}, 0.15 \mathrm{mM}$, approximately equal to the $K_{\mathrm{m}}$ value of CES1 hydrolyzed DME). After shaking the reaction for $10 \mathrm{~min}$ in a $37^{\circ} \mathrm{C}$ incubator, $50 \mu \mathrm{L}$ of the reaction solution was pipetted and mixed with LDR $(50 \mu \mathrm{L})$ to terminate the reaction. Detection was performed in a multi-mode microplate reader (SpectraMax® iD3, Molecular Devices, Austria). All compounds were formulated in chromatographic grade DMSO with a final volume ratio of DMSO of less than $1 \%(\mathrm{v} / \mathrm{v})$.

2.3.2. Inhibition of indole derivatives on CES2-mediated FD hydrolysis. The inhibitory effects toward CES2 were investigated with FD as the specific probe substrate. The reaction procedure mainly includes the following parts: firstly, phosphate buffer (194 $\mu \mathrm{L}, \mathrm{pH} 7.4)$, CES2 enzyme source (HLM, $2 \mu \mathrm{L}$, $0.2 \mathrm{mg} \mathrm{mL} \mathrm{m}^{-1}$, initial concentration), indole derivatives $(2 \mu \mathrm{L})$, and add the positive inhibitor LPA in parallel. The mixture was mixed and placed in a $37^{\circ} \mathrm{C}$ incubator for $10 \mathrm{~min}$, then added with FD $(2 \mu \mathrm{L}, 0.2 \mathrm{mM}$, initial concentration) for $20 \mathrm{~min}$, and an equal volume of acetonitrile (chromatographic grade) was added to the reaction solution to terminate the reaction. Then, $200 \mu \mathrm{L}$ of the mixture was pipetted into the microtiter plate. Place it in the microplate reader for testing. All compounds were formulated in chromatographic grade DMSO with a final volume ratio of DMSO of less than $2 \%(\mathrm{v} / \mathrm{v})$.

2.3.3. Statistical analysis. The half maximal inhibitory concentration $\left(\mathrm{IC}_{50}\right)$ of each compound was determined using various inhibitor concentrations under the same incubation conditions as mentioned above. All values obtained from experiments were expressed as mean $\pm \mathrm{SD}$. The $\mathrm{IC}_{50}$ values of the compounds were evaluated using GraphPad Prism 7.0 (GraphPad Software, Inc., La Jolla, USA) nonlinear regression.

Table 1 Optimization of the reaction conditions for the synthesis of $4 a$

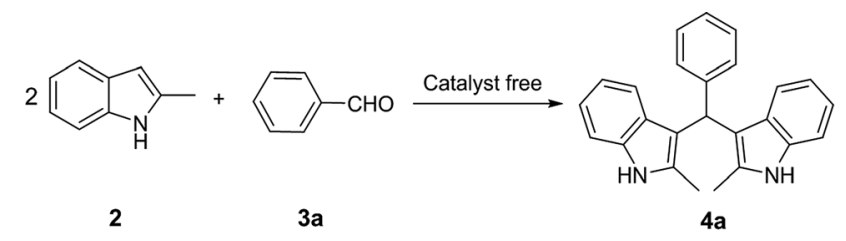

\begin{tabular}{|c|c|c|c|c|}
\hline Entry $^{a}$ & Solvent & Vol./mL & Time/h & Yield $^{b} / \%$ \\
\hline 1 & $\mathrm{EtOH}-\mathrm{H}_{2} \mathrm{O}$ & $0.75 / 0.75$ & 4 & 98 \\
\hline 2 & $\mathrm{EtOH}-\mathrm{H}_{2} \mathrm{O}$ & $0.9 / 0.6$ & 4 & 93 \\
\hline 3 & $\mathrm{EtOH}-\mathrm{H}_{2} \mathrm{O}$ & $0.5 / 1.0$ & 4 & 95 \\
\hline 4 & EtOH- $\mathrm{H}_{2} \mathrm{O}$ & $0.75 / 0.75$ & 5 & 98 \\
\hline 5 & $\mathrm{EtOH}-\mathrm{H}_{2} \mathrm{O}$ & $0.75 / 0.75$ & 3 & 94 \\
\hline $6^{c}$ & $\mathrm{EtOH}-\mathrm{H}_{2} \mathrm{O}$ & $0.75 / 0.75$ & 4 & 90 \\
\hline $7^{d}$ & EtOH- $\mathrm{H}_{2} \mathrm{O}$ & $0.75 / 0.75$ & 4 & 96 \\
\hline
\end{tabular}

${ }^{a}$ The reactions were carried out with $0.5 \mathrm{mmol}$ benzaldehyde and $1.0 \mathrm{mmol}$ indole. ${ }^{b}$ Isolated yield. ${ }^{c}$ At $45{ }^{\circ} \mathrm{C}$ without irradiation of blue LEDs. ${ }^{d}$ Irradiation of white LEDs. 


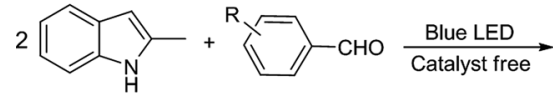

2

3

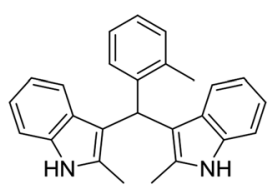

4b, Yield $87 \%$<smiles>COc1ccccc1C(c1c(C)[nH]c2ccccc12)c1c(C)[nH]c2ccccc12</smiles>

4e, Yield $90 \%$<smiles>Cc1[nH]c2ccccc2c1C(c1cccc(Cl)c1)c1c(C)[nH]c2ccccc12</smiles>

$4 \mathbf{i}$, Yield $98 \%$<smiles>Cc1[nH]c2ccccc2c1C(c1ccc(Br)cc1)c1c(C)[nH]c2ccccc12</smiles><smiles>COc1cccc(C(c2c(C)[nH]c3ccccc23)c2c(C)[nH]c3ccccc23)c1</smiles>

4f, Yield $98 \%$<smiles>Cc1[nH]c2ccccc2c1C(c1ccc(Cl)cc1)c1c(C)[nH]c2ccccc12</smiles>

$4 \mathbf{j}$, Yield $92 \%$<smiles>Cc1[nH]c2ccccc2c1C(c1ccccc1[N+](=O)[O-])c1c(C)[nH]c2ccccc12</smiles>

4n, Yield $65 \%$<smiles>Cc1cccc(C(c2c(C)[nH]c3ccccc23)c2c(C)[nH]c3ccccc23)c1</smiles>

4c, Yield $80 \%$<smiles>COc1ccc(C(c2c(C)[nH]c3ccccc23)c2c(C)[nH]c3ccccc23)cc1</smiles>

$4 g$, Yield $60 \%$<smiles>Cc1[nH]c2ccccc2c1C(c1ccccc1Br)c1c(C)[nH]c2ccccc12</smiles>

4k, Yield $95 \%$<smiles>Cc1[nH]c2ccccc2c1C(c1cccc([N+](=O)[O-])c1)c1c(C)[nH]c2ccccc12</smiles><smiles>Cc1ccc(C(c2c(C)[nH]c3ccccc23)c2c(C)[nH]c3ccccc23)cc1</smiles>

4d, Yield $99 \%$<smiles>Cc1[nH]c2ccccc2c1C(c1ccccc1Cl)c1c(C)[nH]c2ccccc12</smiles>

4h, Yield $95 \%$<smiles>Cc1[nH]c2ccccc2c1C(c1cccc(Br)c1)c1c(C)[nH]c2ccccc12</smiles>

4I, Yield $80 \%$<smiles>Cc1[nH]c2ccccc2c1C(c1ccc([N+](=O)[O-])cc1)c1c(C)[nH]c2ccccc12</smiles>

\footnotetext{
${ }^{a}$ The reactions were carried out with $0.5 \mathrm{mmol}$ benzaldehyde and $1.0 \mathrm{mmol}$ indole in $1.5 \mathrm{~mL}$ EtOH- $\mathrm{H}_{2} \mathrm{O}(1: 1)$ under irradiation of blue LEDs. ${ }^{b}$ Isolated yield.
}

\section{Results and discussion}

\subsection{Design synthetic protocols and optimize reaction conditions}

Over the years, a plethora of synthetic protocols has been developed due to the wide range of applications in biomedicine and agriculture of bis(indolyl)methanes (BIMs). ${ }^{46-48}$ Among them, using indoles and aldehydes as substrates is one of the most effective synthesis methods that received more attention. ${ }^{49-52}$ Therefore, the first purpose of this study is to develop facile pathway for the green synthesis of BIMs via the reaction of indole with aldehydes. Recently, visible light as a rich, readily available and renewable clean energy source, ${ }^{53,54}$ has been widely utilized to promote various organic synthetic transformations. ${ }^{55-57}$ In this context, visible light assisted reactions without catalyst meet the requirements of mild reaction conditions and environmental friendliness, which should be the best choice to implement the reaction of indole and aldehydes. Based on the references and our experiences, aqueous ethanol was good solvent for the reaction containing indole and aldehyde, therefore, it was used throughout our study. In view of the inhibitory property of $\beta$-substituted indole derivatives $\mathbf{1 l}-\mathbf{p}$ toward CES2 in Section 3.3 and to realize our envisaged protocol, model reaction of 2-methylindole with benzaldehyde was performed with irradiation by blue light-emitting diodes (LEDs; $15 \mathrm{~W}$ ) at room temperature under catalyst-free 
Table 3 The $\mathrm{IC}_{50}$ values of indole derivatives toward CES2 ${ }^{a}$

\begin{tabular}{llll}
\hline & CES2 IC $_{50}(\mu \mathrm{M})$ & & CES2 IC $50(\mu \mathrm{M})$ \\
\hline $\mathbf{1 a}$ & $24.47 \pm 4.55$ & $\mathbf{4 a}$ & $0.64 \pm 0.13$ \\
$\mathbf{1 b}$ & $11.08 \pm 2.45$ & $\mathbf{4 b}$ & $0.56 \pm 0.16$ \\
$\mathbf{1 c}$ & $3.29 \pm 0.28$ & $\mathbf{4 c}$ & $0.34 \pm 0.091$ \\
$\mathbf{1 d}$ & $>100$ & $\mathbf{4 d}$ & $0.28 \pm 0.027$ \\
$\mathbf{1 e}$ & $>100$ & $\mathbf{4 e}$ & $0.20 \pm 0.044$ \\
$\mathbf{1 f}$ & $4.37 \pm 0.66$ & $\mathbf{4 f}$ & $1.28 \pm 0.24$ \\
$\mathbf{1 g}$ & $9.01 \pm 2.49$ & $\mathbf{4 g}$ & $0.15 \pm 0.032$ \\
$\mathbf{1 h}$ & $20.27 \pm 5.19$ & $\mathbf{4 h}$ & $0.57 \pm 0.086$ \\
$\mathbf{1 i}$ & $7.79 \pm 1.24$ & $\mathbf{4 i}$ & $1.23 \pm 0.37$ \\
$\mathbf{1 j}$ & $4.28 \pm 0.36$ & $\mathbf{4 j}$ & $0.84 \pm 0.23$ \\
$\mathbf{1} \mathbf{k}$ & $>100$ & $\mathbf{4 k}$ & $0.35 \pm 0.091$ \\
$\mathbf{1 l}$ & $2.98 \pm 0.53$ & $\mathbf{4 l}$ & $3.17 \pm 0.81$ \\
$\mathbf{1} \mathbf{1 m}$ & $2.64 \pm 0.35$ & $\mathbf{4 m}$ & $1.21 \pm 0.28$ \\
$\mathbf{1 n}$ & $2.89 \pm 0.30$ & $\mathbf{4 n}$ & $0.19 \pm 0.045$ \\
$\mathbf{1 0}$ & $4.12 \pm 0.84$ & $\mathbf{4 0}$ & $0.35 \pm 0.11$ \\
$\mathbf{1 p}$ & $7.47 \pm 0.77$ & $\mathbf{4 p}$ & $1.22 \pm 0.20$
\end{tabular}

${ }^{a}$ All data presented are averages of at least three separate experiments. condition. Delightedly, the desired product 4 a was obtained in $98 \%$ yield (Table 1 , entry 1 ). The heat would generate due to the use of LED band and the temperature was about $45{ }^{\circ} \mathrm{C}$. Considered this, a control experiment without light irradiation was conducted at $45{ }^{\circ} \mathrm{C}$, but not at room temperature. Based on this result, visible light was proved essential for the reaction, because in the absence it, the yield was reduced (entries 1 and 6). When replace blue LED with white LED, a slight lower score is obtained, but still better than conventional heat method. The solvent was also finely tuned by employing ethanol with water in different volumes and proportions. After some experiments, we found this conversion took place with maximum isolated yield in the mixture of $0.75 \mathrm{~mL}$ ethanol and $0.75 \mathrm{~mL}$ water. Optimization result indicated that reacted 4 hours were adequate for this reaction. Target molecule could form and isolate in 98\% yield after filtration and washing with $50 \%$ ethanol.

\subsection{Substrate scope}

Using the optimized reaction conditions, we examined the generality and scope of the protocol across a range of<smiles>N#CC(C#N)C(c1ccccc1)c1c[nH]c2ccccc12</smiles><smiles>N#CC(C#N)C(c1ccc(Br)cc1)c1c[nH]c2ccccc12</smiles><smiles>COc1ccccc1C(c1c[nH]c2ccccc12)C(C#N)C#N</smiles>

$1 \mathrm{i}$<smiles>Cc1[nH]c2ccccc2c1C(c1cccc(Cl)c1)C(C#N)C#N</smiles><smiles>N#CC(C#N)C(c1ccccc1Cl)c1c[nH]c2ccccc12</smiles><smiles>Cc1ccccc1C(c1c[nH]c2ccccc12)C(C#N)C#N</smiles><smiles>COc1cccc(C(c2c[nH]c3ccccc23)C(C#N)C#N)c1</smiles><smiles>Cc1[nH]c2ccccc2c1C(c1cccc(Br)c1)C(C#N)C#N</smiles><smiles>Cc1cccc(C(c2c(C)[nH]c3ccccc23)C(C#N)C#N)c1</smiles><smiles>N#CC(C#N)C(c1ccc([N+](=O)[O-])cc1)c1c[nH]c2ccccc12</smiles><smiles>N#CC(C#N)C(c1ccc(Cl)cc1)c1cn2ccccc2c1-c1ccccc1</smiles><smiles></smiles><smiles>Cc1[nH]c2ccccc2c1C(c1ccccc1)C(C#N)C#N</smiles><smiles>Cc1c(C(c2ccc([N+](=O)[O-])cc2)C(C#N)C(C)C)c2ccccc2n1[CH]C(C)C</smiles>

Fig. 1 Chemical structures of tested $\beta$-substituted indole derivatives $1 \mathrm{a}-\mathrm{p}$. 
Table 4 The $\mathrm{IC}_{50}$ values of indole derivatives toward CES2 and CES1 ${ }^{a}$

\begin{tabular}{lll}
\hline & CES2 $\mathrm{IC}_{50}(\mu \mathrm{M})$ & CES1 IC $_{50}(\mu \mathrm{M})$ \\
\hline $\mathbf{4 g}$ & $0.15 \pm 0.032$ & $2.90 \pm 0.24$ \\
$\mathbf{4 n}$ & $0.19 \pm 0.045$ & $3.68 \pm 0.43$ \\
$\mathrm{LPA}^{b}$ & $1.72 \pm 0.28$ & $>100$ \\
$\mathrm{BNPP}^{c}$ & $5.66 \pm 0.62$ & $0.24 \pm 0.02$
\end{tabular}

${ }^{a}$ All data presented are averages of at least three separate experiments. ${ }^{b}$ Loperamide, a positive inhibitor against CES2. ${ }^{c}$ Bis- $p$-nitrophenyl phosphate, a positive inhibitor against CES1.

benzaldehyde incorporating various substituents, such as Me, $\mathrm{MeO}, \mathrm{Cl}, \mathrm{Br}$, and $\mathrm{NO}_{2}$. These reactions worked well in most cases, affording the corresponding products in moderate to excellent yields (Table 2). Aromatic ring bearing a weak electronwithdrawing group appeared to afford slightly higher yields compared with benzaldehyde having an electron-donating group. Introduction of strongly electron-withdrawing group on benzene ring such as nitryl was disfavored to the yield of reaction. The presence of substituents at various positions of benzaldehyde appreciably affected the yields too. For instance, methoxyl in meta-position on benzene ring had weak electronwithdrawing inductive effect and no conjugation effect. So, it afforded a better yield than other two methoxyl substituted benzaldehyde (Table 2, 4e-4g). This outcome also showed that introducing strongly electron-withdrawing group in ortho or para positions of phenyl ring would decrease the yield (Table 2, 4n, 4p). However, increasing the electron withdrawing substituents on aromatic ring at the 3-position of aromatic aldehyde gave the desired products in good yields too. In other words, nitro-group on aromatic ring in ortho or para positions, the reactivity of carbonyl was further increased. The electron deficient benzaldehyde, which containing an overactive carbonyl group was disadvantageous to the reaction under this condition. But satisfactory outputs could be furnished if they reacted without irradiation of blue LED. Generally, the electronic effect played a major role in governing the reactivity of the substrates and steric effect was not the dominant factor in the product formation.

\subsection{Evaluation of inhibitory activities against CES1 and CES2}

Following the establishment of these indole derivatives and considering the pharmacophore characters of the indole, a further investigation was carried out to evaluate whether these indole compounds possess potential biological activities against CES2 using FD as specific optical substrate. As shown in Table 2, we firstly focused our attention on the variation of the benzyl moiety of $\beta$-substituted indole derivatives 1a-q. The benzyl unit with substitutes ( $\mathrm{Cl}, \mathrm{Br}, \mathrm{Me}, \mathrm{MeO})$ at 2-position or 3position afforded increased inhibitory effect against CES2 compared with compound 1a. Compound 1 h with 4-methyl on

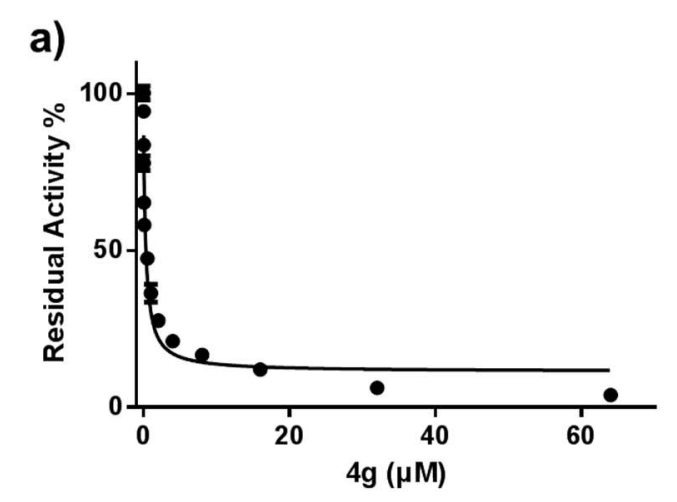

c)

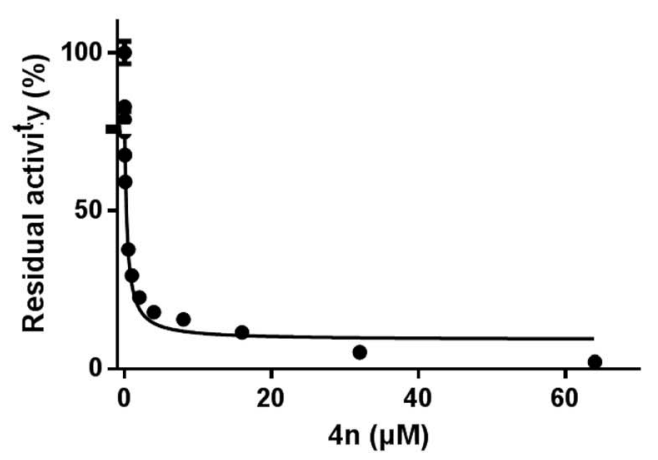

b)

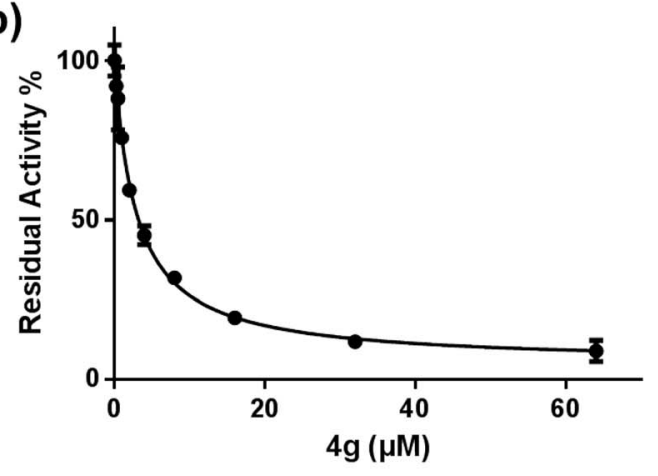

d)

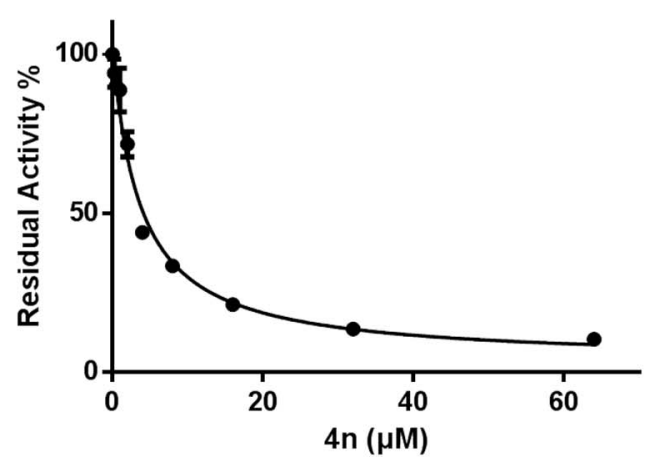

Fig. 2 The dose-dependent inhibition of $4 \mathrm{~g}$ and $4 \mathrm{n}$ against CES2 mediated FD hydrolysis and CES1 mediated DME hydrolysis. Left: the dosedependent inhibition curves of CES2. Right: the dose-dependent inhibition curves of CES1. All data represent the mean of triplicate determinations. 
the benzyl unit exhibited similar trends in CES2 inhibition as compound 1a, but the benzoyl unit with 4-methoxyl (1d), 4chlorine (1e) and 4-nitryl (1k) substitute displayed poor inhibition toward CES2. Further characterizations of compounds 11-p with the variation of indole unit demonstrated that these compound with 2-methyl on indole unit is more beneficial for the inhibitory property of $\beta$-substituted indole derivatives toward CES2.

Following the good inhibitory effects of $\beta$-substituted indole derivatives on CES2, a survey was next carried out to evaluate the inhibitory effect against CES2 of these bis(indolyl)methanes 4ap. To our delight, all tested compounds $\mathbf{4 a - p}$ showed a dramatically increase in the inhibitory effects against CES2 compared with compound $\mathbf{1}$ (Table 3 ). In addition, compounds $\mathbf{4 g}$ and $\mathbf{4 n}$ showed excellent inhibitory effect against CES2 with much lower $\mathrm{IC}_{50}$ value of $0.15 \mu \mathrm{M}$ and $0.19 \mu \mathrm{M}$, respectively. Furthermore, the inhibitory effects of $\beta$-substituted indole derivatives $\mathbf{1 a - q}$ and bis(indolyl)methanes $\mathbf{4 a - p}$ on CES1 were routinely screened using one inhibitor concentrations $(10 \mu \mathrm{M})$ and using D-luciferin methyl ester (DME) as specific optical substrate. As shown in ESI $\dagger$ Fig. 1, a majority of tested these indole derivatives displayed weak inhibitory effects on CES1 at the concentration $(10 \mu \mathrm{M})$, only a few compounds showed relative strong inhibition potentials on CES1-mediated DME hydrolysis. As shown in Table 4, compounds $\mathbf{4 g}$ and $\mathbf{4 n}$ showed reduced inhibitory effect toward CES1 $\left(\mathrm{IC}_{50} 2.90 \mu \mathrm{M}\right.$ and 3.68 $\mu \mathrm{M}$, respectively) in contrast to CES2. In addition, known inhibitors loperamide (LPA) and bis- $p$-nitrophenyl phosphate (BNPP) were tested under identical conditions as positive control for CES2 and CES1, respectively. The result indicated that LPA showed inferior inhibitory effects on CES2 in contrast to compounds $\mathbf{4 g}$ and $\mathbf{4 n}$ (Fig. 2).

\section{Conclusions}

In summary, a green protocol for catalyst free synthesis of BIMs from 2-methylindole and aryl aldehydes with good yields has been accomplished. We anticipate that blue light assisted reaction would offer efficient and cost effective way to obtain this important class of compounds. The reaction is free from hazardous metal or Lewis acid catalyst and uses environmentfriendly solvent. In addition, two kinds of indole derivatives including $\beta$-substituted indoles and BIMs were collected and their inhibitory effects against human carboxylesterases were assayed using FD and DME as specific optical substrate for CES2 and CES1, respectively. The primary SAR analysis revealed that the bisindolyl structure of BIMs is a key factor affecting the inhibitory effects of indole derivatives on CES2. Furthermore, BIMs $\mathbf{4 g}$ and $\mathbf{4 n}$ demonstrated strong inhibitory effects on CES2 ( IC $_{50}, 0.15 \mu \mathrm{M}$ and $0.19 \mu \mathrm{M}$, respectively) and good selectivity over CES1. Further studies directed toward expanding the synthetic utility and evaluating the biological activity of BIMs are currently ongoing in our laboratory.

\section{Conflicts of interest}

There are no conflicts to declare.

\section{Acknowledgements}

We are grateful for financial support from the Department of Science and Technology of Liaoning Province (No. 2019-MS-215, 2019-ZD-0470), the NSF of China (21602219, 81703604, 81803489, and 81773810), the National Key Research and Development Program of China (2017YFC1700200).

\section{References}

1 T. Satoh and M. Hosokawa, Structure, function and regulation of carboxylesterases, Chem.-Biol. Interact., 2006, 162(3), 195-211.

2 S. P. Sanghani, P. C. Sanghani, M. A. Schiel and W. F. Bosron, Human Carboxylesterases: An Update on CES1, CES2 and CES3, Protein Pept. Lett., 2009, 16(10), 1207-1214.

3 D. D. Wang, L. W. Zou, Q. Jin, J. Hou, G. B. Ge and L. Yang, Human carboxylesterases: a comprehensive review, Acta Pharm. Sin. B, 2018, 8(5), 699-712.

4 M. Gabriele, P. Puccini, M. Lucchi, A. Vizziello, P. G. Gervasi and V. Longo, Presence and inter-individual variability of carboxylesterases (CES1 and CES2) in human lung, Biochem. Pharmacol., 2018, 150, 64-71.

5 M. K. Ross and J. A. Crow, Human Carboxylesterases and their role in xenobiotic and endobiotic metabolism, $J$. Biochem. Mol. Toxicol., 2007, 21(4), 187-196.

$6 \mathrm{M}$. Hosokawa, Structure and catalytic properties of carboxylesterase isozymes involved in metabolic activation of prodrugs, Molecules, 2008, 13(2), 412-431.

7 S. P. Sanghani, S. K. Quinney, T. B. Fredenburg, Z. J. Sun, W. I. Davis, D. J. Murry, O. W. Cummings, D. E. Seitz and W. F. Bosron, Carboxylesterases expressed in human colon tumor tissue and their role in CPT-11 hydrolysis, Clin. Cancer Res., 2003, 9(13), 4983-4991.

8 M. J. Hatfield, L. Tsurkan, M. Garrett, T. M. Shaver, J. L. Hyatt, C. C. Edwards, L. D. Hicks and P. M. Potter, Organ-specific carboxylesterase profiling identifies the small intestine and kidney as major contributors of activation of the anticancer prodrug CPT-11, Biochem. Pharmacol., 2011, 81(1), 24-31.

9 R. M. Wadkins, J. L. Hyatt, K. J. P. Yoon, C. L. Morton, R. E. Lee, K. Damodaran, P. Beroza, M. K. Danks and P. M. Potter, Discovery of novel selective inhibitors of human intestinal carboxylesterase for the amelioration of irinotecan-induced diarrhea: synthesis, quantitative structure-activity relationship analysis, and biological activity, Mol. Pharmacol., 2004, 65(6), 1336-1343.

10 J. L. Hyatt, L. Tsurkan, M. Wierdl, C. C. Edwards, M. K. Danks and P. M. Potter, Intracellular inhibition of carboxylesterases by benzil: modulation of CPT-11 cytotoxicity, Mol. Cancer Ther., 2006, 5(9), 2281-2288.

11 A. Alimonti, A. Gelibter, I. Pavese, F. Satta, F. Cognetti, G. Ferretti, D. Rasio, A. Vecchione and M. Di Palma, New approaches to prevent intestinal toxicity of irinotecanbased regimens, Cancer Treat. Rev., 2004, 30(6), 555-562.

12 M. A. Ruby, J. Massart, D. M. Hunerdosse, M. Schonke, J. C. Correia, S. M. Louie, J. L. Ruas, E. Naslund, 
D. K. Nomura and J. R. Zierath, Human Carboxylesterase 2 Reverses Obesity-Induced Diacylglycerol Accumulation and Glucose Intolerance, Cell Rep., 2017, 18(3), 636-646.

13 E. Dominguez, A. Galmozzi, J. W. Chang, K. L. Hsu, J. Pawlak, W. W. Li, C. Godio, J. Thomas, D. Partida, S. Niessen, P. E. O'Brien, A. P. Russell, M. J. Watt, D. K. Nomura, B. F. Cravatt and E. Saez, integrated phenotypic and activity-based profiling links Ces3 to obesity and diabetes, Nat. Chem. Biol., 2014, 10(2), 113-121.

14 Y. Y. Li, M. Zalzala, K. Jadhav, Y. Xu, T. Kasumov, L. Y. Yin and Y. Q. Zhang, Carboxylesterase 2 Prevents Liver Steatosis by Modulating Lipolysis, Endoplasmic Reticulum Stress, and Lipogenesis and Is Regulated by Hepatocyte Nuclear Factor 4 Alpha in Mice, Hepatology, 2016, 63(6), 1860-1874.

15 S. Safe, S. Papineni and S. Chintharlapalli, Cancer chemotherapy with indole-3-carbinol, bis(3'-indolyl) methane and synthetic analogs, Cancer Lett., 2008, 269(2), 326-338.

16 M. P. Leze, M. Le Borgne, P. Marchand, D. Loquet, M. Kogler, G. Le Baut, A. Palusczak and R. W. Hartmann, 2- and 3[(Aryl)(azolyl)methyl]indoles as Potential Non-steroidal Aromatase Inhibitors, J. Enzyme Inhib. Med. Chem., 2004, 19(6), 549-557.

17 G. Sivaprasad, P. T. Perumal, V. R. Prabavathy and N. Mathivanan, Synthesis and anti-microbial activity of pyrazolylbisindoles - Promising anti-fungal compounds, Bioorg. Med. Chem. Lett., 2006, 16(24), 6302-6305.

18 S. Malhotra, S. Balwani, A. Dhawan, B. K. Singh, S. Kumar, R. Thimmulappa, S. Biswal, C. E. Olsen, E. Van der Eycken, A. K. Prasad, B. Ghosh and V. S. Parmar, Synthesis and biological activity evaluation of $\mathrm{N}$-protected isatin derivatives as inhibitors of ICAM-1 expression on human endothelial cells, MedChemComm, 2011, 2(8), 743-751.

19 K. Sujatha, P. T. Perumal, D. Muralidharan and M. Rajendran, Synthesis, analgesic and anti-inflammatory activities of bis(indolyl)methanes, Indian J. Chem., Sect. B: Org. Chem. Incl. Med. Chem., 2009, 48(2), 267-272.

20 C. Praveen, P. DheenKumar, D. Muralidharan and P. T. Perumal, Synthesis, antimicrobial and antioxidant evaluation of quinolines and bis(indolyl)methanes, Bioorg. Med. Chem. Lett., 2010, 20(24), 7292-7296.

21 P. J. Praveen, P. S. Parameswaran and M. S. Majik, Bis(indolyl)methane Alkaloids: Isolation, Bioactivity, and Syntheses, Synthesis, 2015, 47(13), 1827-1837.

22 A. J. Kochanowska-Karamyan and M. T. Hamann, Marine Indole Alkaloids: Potential New Drug Leads for the Control of Depression and Anxiety, Chem. Rev., 2010, 110(8), 44894497.

23 C. Ramesh, V. Kavala, C. W. Kuo, B. R. Raju and C. F. Yao, An Unprecedented Route for the Synthesis of 3,3 '-Bisndoles by Reductive Cyclization of 3-[2-Nitro-1-(2-nitrophenyl)ethyl]$1 \mathrm{H}$-indoles Mediated by Iron/Acetic Acid, Eur. J. Org. Chem., 2010, (20), 3796-3801.

24 M. Terada, K. Moriya, K. Kanomata and K. Sorimachi, Chiral Bronsted Acid Catalyzed Stereoselective Addition of Azlactones to 3-Vinylindoles for Facile Access to
Enantioenriched Tryptophan Derivatives, Angew. Chem., Int. Ed., 2011, 50(52), 12586-12590.

25 U. C. Rajesh, J. F. Wang, S. Prescott, T. Tsuzuki and D. S. Rawatt, RGO/ZnO Nanocomposite: An Efficient, Sustainable, Heterogeneous, Amphiphilic Catalyst for Synthesis of 3-Substituted Indoles in Water, ACS Sustainable Chem. Eng., 2015, 3(1), 9-18.

26 J. Xiao, H. Wen, L. Wang, L. B. Xu, Z. H. Hao, C. L. Shao and C. Y. Wang, Catalyst-free dehydrative $S(N) 1$-type reaction of indolyl alcohols with diverse nucleophiles on water, Green Chem., 2016, 18(4), 1032-1037.

27 G. Gao, Y. Han and Z. H. Zhang, Catalyst Free Synthesis of Bis(Indolyl)Methanes and 3,3-Bis(Indolyl)oxindoles in Aqueous Ethyl Lactate, ChemistrySelect, 2017, 2(35), 1156111564.

28 M. L. Deb, B. Deka, P. J. Saikia and P. K. Baruah, Basepromoted three-component cascade approach to unsymmetrical bis(indolyl)methanes, Tetrahedron Lett., 2017, 58(20), 1999-2003.

29 C. W. Lu, J. J. Wang, Y. H. Liu, W. J. Shan, Q. Sun and L. Shi, A combination of green solvent and ultrasonic irradiation promotes the catalyst-free reaction of aldehydes, indoles and Meldrum's acid, Res. Chem. Intermed., 2017, 43(2), 943-949.

30 H. L. Ruan, Y. Lv, S. J. Yu, C. W. Lv and Y. An, Water Assisted and Choline Chloride-Dimethylurea Deep Eutectic Salts as Catalyst Towards the Attractive Reaction of Indole, Benzaldehyde, and Malononitrile, Heterocycles, 2018, 96(7), 1266-1274.

31 M. Shimizu, T. Fukami, M. Nakajima and T. Yokoi, Screening of Specific Inhibitors for Human Carboxylesterases or Arylacetamide Deacetylase, Drug Metab. Dispos., 2014, 42(7), 1103-1109.

32 J. Wang, E. T. Williams, J. Bourgea, Y. N. Wong and C. J. Patten, Characterization of Recombinant Human Carboxylesterases: Fluorescein Diacetate as a Probe Substrate for Human Carboxylesterase 2, Drug Metab. Dispos., 2011, 39(8), 1329-1333.

33 Z.-M. Liu, L. Feng, J. Hou, X. Lv, J. Ning, G.-B. Ge, K.-W. Wang, J.-N. Cui and L. Yang, A ratiometric fluorescent sensor for highly selective detection of human carboxylesterase 2 and its application in living cells, Sens. Actuators, B, 2014, 205, 151-157.

34 Q. Jin, L. Feng, D. D. Wang, Z. R. Dai, P. Wang, L. W. Zou, Z. H. Liu, J. Y. Wang, Y. Yu, G. B. Ge, J. N. Cui and L. Yang, A Two-Photon Ratiometric Fluorescent Probe for Imaging Carboxylesterase 2 in Living Cells and Tissues, ACS Appl. Mater. Interfaces, 2015, 7(51), 28474-28481.

35 Q. Jin, L. Feng, D. D. Wang, J. J. Wu, J. Hou, Z. R. Dai, S. G. Sun, J. Y. Wang, G. B. Ge, J. N. Cui and L. Yang, A highly selective near-infrared fluorescent probe for carboxylesterase 2 and its bioimaging applications in living cells and animals, Biosens. Bioelectron., 2016, 83, 193-199.

36 D. D. Wang, Q. Jin, L. W. Zou, J. Hou, X. Lv, W. Lei, H. L. Cheng, G. B. Ge and L. Yang, A bioluminescent sensor for highly selective and sensitive detection of 
human carboxylesterase 1 in complex biological samples, Chem. Commun., 2016, 52(15), 3183-3186.

37 D. D. Wang, Q. Jin, J. Hou, L. Feng, N. Li, S. Y. Li, Q. Zhou, L. W. Zou, G. B. Ge, J. G. Wang and L. Yang, Highly sensitive and selective detection of human carboxylesterase 1 activity by liquid chromatography with fluorescence detection, J. Chromatogr. B: Anal. Technol. Biomed. Life Sci., 2016, 1008, 212-218.

38 D. D. Wang, L. W. Zou, Q. Jin, J. Hou, G. B. Ge and L. Yang, Recent progress in the discovery of natural inhibitors against human carboxylesterases, Fitoterapia, 2017, 117, 84-95.

39 L. W. Zou, Q. Jin, D. D. Wang, Q. K. Qian, D. C. Hao, G. B. Ge and L. Yang, Carboxylesterase Inhibitors: An Update, Curr. Med. Chem., 2018, 25(14), 1627-1649.

40 L. W. Zou, Y. G. Li, P. Wang, K. Zhou, J. Hou, Q. Jin, D. C. Hao, G. B. Ge and L. Yang, Design, synthesis, and structure-activity relationship study of glycyrrhetinic acid derivatives as potent and selective inhibitors against human carboxylesterase 2, Eur. J. Med. Chem., 2016, 112, 280-288.

41 X. Z. Bao, S. Q. Wei, X. K. Qian, J. P. Qu, B. M. Wang, L. W. Zou and G. B. Ge, Asymmetric Construction of a Multi-Pharmacophore-Containing Dispirotriheterocyclic Scaffold and Identification of a Human Carboxylesterase 1 Inhibitor, Org. Lett., 2018, 20(11), 3394-3398.

42 L. W. Zou, T. Y. Dou, P. Wang, W. Lei, Z. M. Weng, J. Hou, D. D. Wang, Y. M. Fan, W. D. Zhang, G. B. Ge and L. Yang, Structure-Activity Relationships of Pentacyclic Triterpenoids as Potent and Selective Inhibitors against Human Carboxylesterase 1, Front. Pharmacol., 2017, 8, 435.

43 P. F. Song, Y. D. Zhu, H. Y. Ma, Y. N. Wang, D. D. Wang, L. W. Zou, G. B. Ge and L. Yang, Discovery of natural pentacyclic triterpenoids as potent and selective inhibitors against human carboxylesterase 1, Fitoterapia, 2019, 137.

44 L. G. Tsurkan, M. J. Hatfield, C. C. Edwards, J. L. Hyatt and P. M. Potter, Inhibition of human carboxylesterases hCE1 and hiCE by cholinesterase inhibitors, Chem.-Biol. Interact., 2013, 203(1), 226-230.

45 K. I. Umehara, M. Zollinger, E. Kigondu, M. Witschi, C. Juif, F. Huth, H. Schiller, K. Chibale and G. Camenisch, Esterase phenotyping in human liver in vitro: specificity of carboxylesterase inhibitors, Xenobiotica, 2016, 46(10), 862867.

46 A. Kumar, M. K. Gupta, M. Kumar and D. Saxena, Micelle promoted multicomponent synthesis of 3-amino alkylated indoles via a Mannich-type reaction in water, $R S C A d v$, 2013, 3(6), 1673-1678.
47 X. Zhu, X. Q. Zhou and D. S. Xiang, Ga(Iii) Catalyzed Addition of Indole Derivatives and Different Propiolates, Heterocycles, 2015, 91(8), 1637-1644.

48 J. C. Xiang, J. G. Wang, M. Wang, X. G. Meng and A. X. Wu, One-pot total synthesis of streptindole, arsindoline $\mathrm{B}$ and their congeners through tandem decarboxylative deaminative dual-coupling reaction of amino acids with indoles, Org. Biomol. Chem., 2015, 13(14), 4240-4247.

49 S. R. Mendes, S. Thurow, F. Penteado, M. S. da Silva, R. A. Gariani, G. Perin and E. J. Lenardao, Synthesis of bis(indolyl)methanes using ammonium niobium oxalate (ANO) as an efficient and recyclable catalyst, Green Chem., 2015, 17(8), 4334-4339.

50 S. Imran, M. Taha, N. H. Ismail, S. Fayyaz, K. M. Khan and M. I. Choudhary, Synthesis of novel bisindolylmethanes: New carbonic anhydrase II inhibitors, docking, and 3D pharmacophore studies, Bioorg. Chem., 2016, 68, 90-104.

51 C. Grosso, A. L. Cardoso, A. Lemos, J. Varela, M. J. Rodrigues, L. Custodio, L. Barreira and T. M. V. D. P. E. Melo, Novel approach to bis(indolyl)methanes: de novo synthesis of 1hydroxyiminomethyl derivatives with anti-cancer properties, Eur. J. Med. Chem., 2015, 93, 9-15.

52 T. Abe, S. Nakamura, R. Yanada, T. Choshi, S. Hibino and M. Ishikura, One-Pot Construction of 3,3'Bisindolylmethanes through Bartoli Indole Synthesis, Org. Lett., 2013, 15(14), 3622-3625.

53 C. K. Prier, D. A. Rankic and D. W. C. MacMillan, Visible Light Photoredox Catalysis with Transition Metal Complexes: Applications in Organic Synthesis, Chem. Rev., 2013, 113(7), 5322-5363.

54 J. R. Chen, X. Q. Hu, L. Q. Lu and W. J. Xiao, Visible light photoredox-controlled reactions of $\mathrm{N}$-radicals and radical ions, Chem. Soc. Rev., 2016, 45(8), 2044-2056.

55 E. Larionov, M. M. Mastandrea and M. A. Pericas, Asymmetric Visible-Light Photoredox CrossDehydrogenative Coupling of Aldehydes with Xanthenes, ACS Catal., 2017, 7(10), 7008-7013.

56 Q. S. Liu, L. L. Wang, H. L. Yue, J. S. Li, Z. D. Luo and W. Wei, Catalyst-free visible-light-initiated oxidative coupling of aryldiazo sulfones with thiols leading to unsymmetrical sulfoxides in air, Green Chem., 2019, 21(7), 1609-1613.

57 Z. F. Li, H. Song, R. Guo, M. H. Zuo, C. F. Hou, S. N. Sun, X. He, Z. Z. Sun and W. Y. Chu, Visible-light-induced condensation cyclization to synthesize benzimidazoles using fluorescein as a photocatalyst, Green Chem., 2019, 21(13), 3602-3605. 